\title{
Genome-wide Response of Normal WI-38 Human Fibroblast Cells to 1,763 MHz Radiofrequency Radiation
}

\author{
Chang-Nim Im, Eun-Hye Kim, Ae-Kyung Park \\ and Woong-Yang Park*
}

Genomics Core Laboratory and Departments of Biochemistry and Molecular Biology, Seoul National University College of Medicine, Seoul 110-799, Korea

\begin{abstract}
Increased exposure of human to RF fields has raised concerns for its potential adverse effects on our health. To address the biological effects of RF radiation, we used genome wide gene expression as the indicator. We exposed normal WI-38 human fibroblast cells to $1763 \mathrm{MHz}$ mobile phone RF radiation at a specific absorption rate (SAR) of $60 \mathrm{~W} / \mathrm{kg}$ with an operating cooling system for $24 \mathrm{~h}$. There were no alterations in cell numbers or morphology after RF exposure. Through microarray analysis, we identified no differentially expressed genes (DEGs) at the 0.05 significance level after controlling for multiple testing errors with the Benjaminiochberg false discovery rate (BH FDR) method. Meanwhile, 82 genes were differentially expressed between RF-exposed cells and controls when the significance level was set at 0.01 without correction for multiple comparisons. We found that 24 genes $(0.08 \%$ of the total genes examined) were changed by more than 1.5-fold on RF exposure. However, significant enrichment of any gene set or pathway was not observed from the functional annotation analysis. From these results, we did not find any evidence that non-thermal RF radiation at a $60-\mathrm{W} / \mathrm{kg}$ SAR significantly affects cell proliferation or gene expression in WI-38 cells.
\end{abstract}

Keywords: radiofrequency radiation, microarray

\section{Introduction}

Recent advances in mobile phone technology have led to exponential use of mobile phone communication around the world. This increasing exposure of human to RF fields has raised concerns for its potential adverse effects on our health. It is clear that ionizing radiation, such as X-ray, affects biological systems, while it is still

*Corresponding author: E-mail wypark@snu.ac.kr Tel +82-2-740-8241, Fax +82-2-744-4534 Accepted 12 February 2010 unclear and inconclusive whether non ionizing low-energy RF radiation could have effects on them. Although there have been a lot of studies of RF effects on biological systems for various aspects, most of them have focused on stress proteins, such as HSP, and MAPK signaling or DNA damages (Belyaev et al., 2006; Chauhan et al., 2006; Friedman et al., 2007; Huang et al., 2008; Lee et al., 2006; Sanchez et al., 2007; Sanchez et al., 2008, Verschaeve et al., 2009). For instance, Friedman et al. (2007) found that exposure of HeLa and Rat1 cells to $875 \mathrm{MHz}$ RF radiation induces the activation of the ERK cascade through ROS generation via NADH oxidase but not that of JNKs or p38 MAPKs. However, we previously reported that the phosphorylation of MAPKs (ERK, JNK, and p38) did not change after exposure of auditory hair cells to 1763 $\mathrm{MHz}$ at a 20-W/kg SAR for up to $2 \mathrm{~h}$ (Huang et al., 2008).

However, RF radiation can affect not only specific genes but also whole genome. If RF radiation exposure induces any biological effects in human, it must change cell behavior and gene expression (McNamee et al., 2009; Vanderstraeten et al., 2008). To date, some microarray analyses have been performed to elucidate the effects of RF radiation on biological systems (Chauhan et al., 2007; Huang et al., 2008; Lee et al., 2006; Lee et al., 2007; Paparini et al., 2009; Qutob et al., 2006; Sanchez et al., 2007; Whitehead et al., 2006; Zeng et al., 2006; Zhao et al., 2007). For example, non-thermal $\mathrm{RF}$ radiation did not affect gene expression in U87MG glioblastoma cells exposed to $1.9 \mathrm{GHz}$ RF at SARs from 0.1 to $10 \mathrm{~W} / \mathrm{kg}$ for $4 \mathrm{~h}$ and $24 \mathrm{~h}$, respectively (Qutob et al., 2006; Chauhan et al., 2007). It has been reported that analysis of gene expression identified a handful of consistently changed genes in MCF-7 cells after exposure to RF radiation at a low SAR (up to $3.5 \mathrm{~W} / \mathrm{kg}$ ) for $24 \mathrm{~h}$. However, these differentially expressed genes were not confirmed by quantitative RT-PCR, implying that the observed effects might have occurred by chance (Zeng et al., 2006). Similarly, RF exposure to $\mathrm{C} 3 \mathrm{H} 10 \mathrm{~T} 1 / 2$ cells at a $5-\mathrm{W} / \mathrm{kg}$ SAR induced no greater changes in gene expression compared to the sham group (Whitehead et al., 2006). In addition, we previously reported unchangeability in the phosphorylation of MAPKs, such as ERK, JNK, and p38, after exposure of auditory hair cells to $1,763 \mathrm{MHz}$ at a $20-\mathrm{W} / \mathrm{kg}$ SAR for up to $2 \mathrm{~h}$. Moreover, neither any cell cycle change nor DNA damage was detected under these conditions. 
Meanwhile, a genome wide analysis of gene expression indicated that some genes, including cytokine receptor genes, were downregulated upon RF radiation, but they were not directly related to cell proliferation or DNA damage responses (Huang et al., 2008).

Although most studies on the biological effects of RF exposure could not detect any molecular changes, some reports demonstrated RF-specific gene expression (Belyaev et al., 2006; Lee et al., 2005; Nylund et al., 2006). For example, Lee et al. (2005) used the serial analysis of gene expression (SAGE) technique and found that $2.45 \mathrm{GHz}$ RF radiation at a $10-\mathrm{W} / \mathrm{kg}$ SAR for $2 \sim 6$ $\mathrm{h}$ affected the expression of 221 genes, including apoptosis-related genes and cell cycle genes, in human HL-60 cells without a significant increase of HSP expression. Nylund et al. (2006) reported that two variants of a human endothelial cell line responded differently to $900 \mathrm{MHz}$ GSM signal mobile phone radiation (Nylund et al., 2006). With regard to the effect of RF exposure to rat brain, Belyaev et al. (2006) reported that GSM at $915 \mathrm{MHz}$ induced no detectable DNA double-stranded breaks or changes in chromatin conformation but affected the expression of genes related to neurotransmitter regulation, blood brain barrier, and melatonin production in rat brain cells. Taken together, this evidence is controversial and not reproducible, although we could consider that different biological samples and different species might respond differently to $\mathrm{RF}$ radiation. To assess the biological effect of RF radiation, most studies using microarray have applied relatively low SARs $(0.1 \sim 20 \mathrm{~W} / \mathrm{kg})$ to cancer cells or tissues.

In this study, we tried to use genome wide gene expression as the indicator to assess the biological effect of RF radiation at high SARs. We exposed normal WI-38 human fibroblast cells to $1,763 \mathrm{MHz}$ RF radiation at a $60-\mathrm{W} / \mathrm{kg}$ SAR for $24 \mathrm{~h}$ and performed microarray to analyze the genome wide response to RF radiation.

\section{Methods}

\section{Cell culture}

Normal WI-38 human lung fibroblast cells were purchased from ATCC and grown in DMEM (Wellgene, Korea), supplemented with $10 \%$ heat-inactivated fetal bovine serum (FBS), $100 \mathrm{mg} / \mathrm{ml}$ streptomycin, and 100 $\mathrm{U} / \mathrm{ml}$ penicillin (Invitrogen, Carlsbad, CA, USA), at $37^{\circ} \mathrm{C}$ in a $5 \% \mathrm{CO}_{2}$ incubator. The cells from passage 18 to 21 were used for this study. Morphological changes in the cells were observed under a phase contrast microscope (magnification 100X), and cell numbers were checked using a hemocytometer.

\section{Radiofrequency (RF) radiation exposure system}

The conditions for RF exposure were described in a previous study (Lee et al., 2006). Briefly, a real Code Domain Multiple Access (CDMA) signal at $1,762.5 \mathrm{MHz}$ was applied for RF exposure. The exposure system was first equilibrated for $2 \mathrm{~h}$, and WI-38 cells in a 100-mm culture dish containing $18 \mathrm{ml}$ of growth medium were exposed at SAR values of $60 \mathrm{~W}$ per $\mathrm{kg}$ for $24 \mathrm{~h}$ with the operating cooling system. Before and after radiation exposure, the temperature of each sample was measured. All exposures were performed in triplicate independently. Cells were immediately harvested and processed for further analysis. Unexposed cells were also divided separately and cultured at $37^{\circ} \mathrm{C}$ in a $5 \% \mathrm{CO}_{2}$ incubator as a control $(n=3)$.

\section{RNA extraction and Affymetrix gene chip proc- essing}

Total RNA was extracted by using the Qiagen RNeasy Mini kit. (Qiagen $\mathrm{GmbH}$, Hilden, Germany). The purity and concentration of RNA were determined by a NanoDrop spectrophotometer (NanoDrop Technologies, Wilmington, DE, USA) and Agilent Bioanalyzer (Agilent Technologies, Santa Clara, CA, USA). The RNA was amplified and labeled according to the Affymetrix GeneChip Whole Transcript (WT) Sense Target Labeling protocol. The resulting labeled cDNA was hybridized to Affymetrix Human Gene 1.0 ST arrays and scanned. The scanned raw expression values were background-corrected, normalized, and summarized using the RMA approach in the Bioconductor "affy" package. The resulting log2transformed data were used for further analyses.

\section{Identification of differentially expressed genes (DEGs)}

A nonspecific filtering was performed to remove the noninformative probe sets with low variability, because these probe sets may lack the sensitivity for us to infer differential expression. Only the probe sets that had a standard deviation above the value of shorth (the mean of the shortest interval containing half of the data) were included. Differentially expressed probe sets were identified using linear models of the "limma" package from Bioconductor, applying the moderated t-statistics based on an empirical Bayes approach. Comparisons were made between two groups: three replicates that were exposed to $1,763 \mathrm{MHz} R F$ at an SAR of $60 \mathrm{~W} / \mathrm{kg}$ for 24 hours and three controls without RF exposure. The Benjamini-Hochberg false discovery rate-adjusted $p$ value (BH FDR $p$ value) was used for correction of multiple 
A

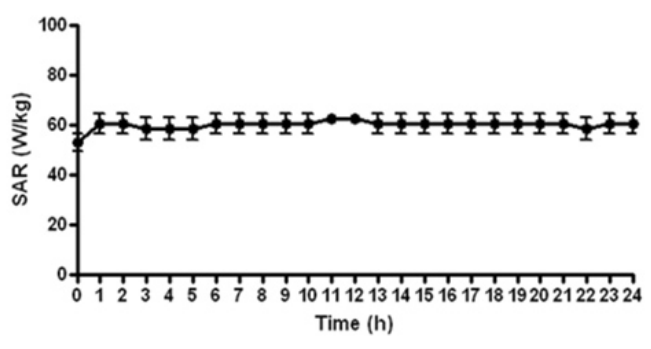

B

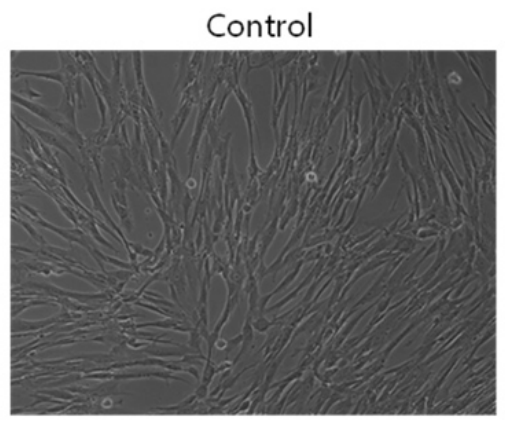

C

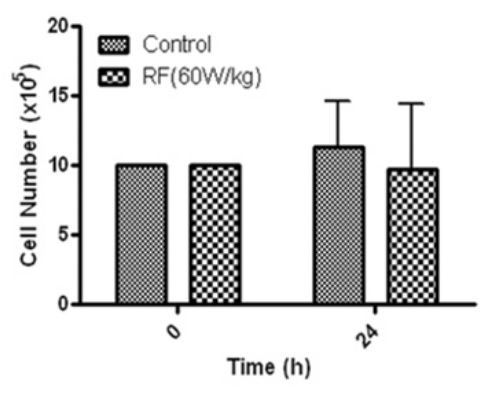

Fig. 1. Monitoring SAR values for $1763 \mathrm{MHz}$ RF radiation for $24 \mathrm{~h}$. (A) cell morphology and cell numbers $(B, C)$ after RF. testing errors. The DAVID bioinformatics resources (http://david.abcc.ncifcrf.gov) were used to detect overrepresented GO categories.

\section{Results and Discussion}

To understand the biological effect of RF radiation, we exposed WI-38 cells to $1,763 \mathrm{MHz}$ RF at a high SAR of $60 \mathrm{~W} / \mathrm{kg}$ for 24 hours with an operating cooling system. We recorded the output of the RF exposure system and also measured the temperature of the medium for each sample right after RF exposure. Even though there were some variations in SAR, RF radiation was almost constantly maintained for 24 hours (Fig. 1A). No significant changes were examined between RF-exposed cells and unexposed cells in cell number or morphology (Fig. 1B and $\mathrm{C}$ ).

In the next step, we performed microarray, covering 28,869 genes, with the samples above to check the genome-wide gene expression. No significant DEGs were identified at the 0.05 significance level after controlling for multiple testing errors with the BH FDR method, implying that no statistically significant change was induced by RF exposure when the increase in temperature by $\mathrm{RF}$ was effectively regulated at $37^{\circ} \mathrm{C}$. When the significance level was set at 0.01 without correction for multiple comparisons, 82 genes appeared to be differentially expressed between RF-exposed cells and controls; however, the smallest FDR-corrected p-value was
0.64 (data not shown). Table 1 presents a list of 24 genes, including developmental pluripotency-associated 3 (DPPA3) and complement component 5 (C5), with $p$-value $<0.01$ and fold-change $\geq 1.5$, showing that the differential expression was not statistically significant because the FDR-corrected p-values for most genes were 1.00 . Furthermore, we did not recognize any statistically significantly enriched gene sets or pathways from the functional annotation analysis with 82 transcripts.

In the present study, we applied RF radiation at a high SAR value to cells, but we did not observe significant changes in cell numbers or morphology. Also, we found that 24 genes $(0.08 \%$ of total genes examined) were changed by more than 1.5 -fold on RF exposure. These results were similar with those of our previous studies, because there were no significant changes in cell cycle in auditory hair cells or Jurkat $\mathrm{T}$ cells after exposure to $1,763 \mathrm{MHz}$ at a $10-$ or $20-\mathrm{W} / \mathrm{kg}$ SAR, respectively, for up to $48 \mathrm{~h}$. In addition, even though some genes, including cytokine receptor genes, were down-regulated upon RF radiation, they were not directly related to cell proliferation, and also, 29 genes that were changed on RF exposure represented just $0.09 \%$ of the total genes examined in the microarray (Huang et al., 2008). In this study, we used a different cell line and RF radiation dosage, as well as RF exposure duration, from a previous study, but there were no significant alterations in gene expression or cell pro- 
Table 1. List of genes with $p$ value $<0.01$ and fold-change $\geq 1.5$

\begin{tabular}{|c|c|c|c|c|c|c|}
\hline $\begin{array}{l}\text { Genebank/ } \\
\text { Ensembl }\end{array}$ & Gene & Gene full name & $\begin{array}{l}\text { Affymetrix } \\
\text { transcript } \\
\text { cluster id }\end{array}$ & $\begin{array}{l}\text { Fold } \\
\text { change }\end{array}$ & $p$ value & $\begin{array}{c}\mathrm{BH} \\
\mathrm{FDR} \\
\mathrm{p} \text { value }\end{array}$ \\
\hline NM_199286 & DPPA3 & Developmental pluripotency associated 3 & 7953665 & 0.62 & 0.00072 & 1.00 \\
\hline NM_018652 & GOLGA6B & Golgi autoantigen, golgin subfamily a, $6 \mathrm{~B}$ & 7984662 & 0.83 & 0.00084 & 1.00 \\
\hline NM_001013 & RPS9 & Ribosomal protein S9 & 8031152 & 0.68 & 0.0011 & 1.00 \\
\hline AK303164 & BCORL2 & BCL6 co-repressor-like 2 & 8177229 & 0.62 & 0.0011 & 1.00 \\
\hline NM_001100817 & TCEB3CL & Transcription elongation factor B polypeptide 3C-like & 8023152 & 1.34 & 0.0011 & 1.00 \\
\hline NR_002716 & RNU2-1 & RNA, U2 small nuclear 1 & 8019709 & 0.76 & 0.0014 & 1.00 \\
\hline NM_030631 & SLC25A21 & $\begin{array}{l}\text { Solute carrier family } 25 \text { (mitochondrial } 21 \\
\text { oxodicarboxylate carrier), member }\end{array}$ & 7978692 & 0.60 & 0.0015 & 1.00 \\
\hline NM_033378 & CGB2 & Chorionic gonadotropin, beta polypeptide 2 & 8030181 & 0.73 & 0.0020 & 1.00 \\
\hline NM_006929 & SKIV2L & Superkiller viralicidic activity 2-like (S. cerevisiae) & 8178136 & 1.01 & 0.0028 & 1.00 \\
\hline AK054626 & FLJ30064 & Hypothetical protein LOC644975 & 8134460 & 0.70 & 0.0029 & 1.00 \\
\hline NR_023380 & CCDC144C & Coiled-coil domain containing $144 \mathrm{C}$ & 8005679 & 0.62 & 0.0031 & 1.00 \\
\hline NM_173619 & MGC34761 & Hypothetical protein MGC34761 & 7997010 & 0.71 & 0.0053 & 1.00 \\
\hline NR_002163 & OR7E37P & $\begin{array}{l}\text { Olfactory receptor, family } 7 \text {, subfamily } E \text {, } \\
\text { member } 37 \text { pseudogene }\end{array}$ & 8042574 & 0.79 & 0.0056 & 1.00 \\
\hline NM_002263 & KIFC1 & Kinesin family member $\mathrm{C} 1$ & 8118669 & 0.69 & 0.0066 & 1.00 \\
\hline BC121813 & FAM74A4 & Family with sequence similarity 74 , member $\mathrm{A} 4$ & 8161407 & 0.66 & 0.0085 & 1.00 \\
\hline NM_001735 & C5 & Complement component 5 & 8163839 & -0.74 & 0.00026 & 0.97 \\
\hline NM_004639 & BAT3 & HLA-B associated transcript 3 & 8124967 & -1.24 & 0.00093 & 1.00 \\
\hline NM_005155 & РPT2 & Palmitoyl-protein thioesterase 2 & 8118509 & -0.98 & 0.0012 & 1.00 \\
\hline NM_152742 & GPC2 & Glypican 2 & 8141463 & -0.60 & 0.0015 & 1.00 \\
\hline NM_033468 & ZNF257 & Zinc finger protein 257 & 8027323 & -0.88 & 0.0029 & 1.00 \\
\hline NM_004426 & PHC1 & Polyhomeotic homolog 1 (Drosophila) & 7953812 & -0.79 & 0.0050 & 1.00 \\
\hline NM_013993 & DDR1 & Discoidin domain receptor tyrosine kinase 1 & 8117900 & -0.68 & 0.0052 & 1.00 \\
\hline NR_015406 & RP5-1022P6.6 & Hypothetical LOC149837 & 8064866 & -0.85 & 0.0073 & 1.00 \\
\hline NM 001079527 & FAM153C & Family with sequence similarity 153 member $C$ & 8110417 & -065 & 00099 & 100 \\
\hline
\end{tabular}

liferation between RF-exposed cells and control cells. Moreover, the functional annotation analysis with 82 genes showed no gene sets or pathways that were significantly enriched, suggesting that these genes might not specifically but randomly respond to RF radiation by chance. Our finding is also consistent with the other reports that non-thermal RF fields did not affect gene expression in a human glioblastoma cell line, U87MG, or mouse whole brain (Paparini et al., 2009; Qutob et al., 2006). Takashima et al. (2006) also found no changes in cell proliferation with continuous exposure at up to 100 $\mathrm{W} / \mathrm{kg}$ at physiological temperature. Recently Paparini et al. (2009) showed that when less stringent constraints were adopted to analyze the microarray data, 75 genes were changed following GSM $1,800 \mathrm{MHz}$ exposure. However, these genes were not confirmed by q RT$\mathrm{PCR}$, implicating that there was no consistent change in gene expression of whole mouse brain upon RF exposure. Among the 75 genes, there were no shared genes with our 24 genes, although there were differences in biological samples, applied RF radiation, and exposure duration.

Since we maintained the temperature of the media at the physiological range and heat shock proteins did not change upon RF exposure, our results suggest that non-thermal RF radiation may not affect cell proliferation or gene expression, unlike thermal RF radiation. With regard to the thermal effect of RF radiation, a comparison of cellular responses to thermal $\mathrm{RF}$ radiation and heat shock may be useful to understand the characteristics of each stressor at the genomic level. Moreover, it may be interesting to assess whether the cellular response to thermal RF radiation may be different from other stressors, such as UV and ionizing radiation.

There are several limitations of our study. First, we did not examine some possible effects that might appear in prolonged periods of recovery time (i.e., 48 or 72 hrs after exposure), which can be performed in a future study to ensure that non-thermal RF radiation does not affect cell proliferation. Second, we did not investigate the effects of RF in a dose-dependent manner, varying the exposure time and SAR value. However, the experimental condition used here was one of the extreme conditions that were employed in many previous studies (McNamee et al., 2009). Another limitation of our study is that we examined the effect of RF radiation in 
only one normal cell line, which does not necessarily imply that the same result will be obtained in other normal cells. Thus, further investigation in various normal cell lines will provide a fuller understanding of the effect of RF in humans.

\section{Acknowledgments}

This research was supported by the IT R\&D program of MIC/ITA (2007-F-043-01, Study on Diagnosis and Protection Technology based on EM) and Basic Science Research Program through the National Research Foundation of Korea (NRF), funded by the Ministry of Education, Science, and Technology (No. 2009-0083512).

\section{References}

Belyaev, I.Y., Koch, C.B., Terenius, O., Roxström-Lindquist, K., Malmgren, L.O., H Sommer, W., Salford, L.G., and Persson, B.R. (2006). Exposure of rat brain to $915 \mathrm{MHz}$ GSM microwaves induces changes in gene expression but not double stranded DNA breaks or effects on chromatin conformation. Bioelectromagnetics 27, 295-306.

Chauhan, V., Mariampillai, A., Gajda, G.B., Thansandote, A., and McNamee, J.P. (2006). Analysis of proto-oncogene and heat-shock protein gene expression in human derived cell-lines exposed in vitro to an intermittent 1.9 $\mathrm{GHz}$ pulse-modulated radiofrequency field. Int. J. Radiat. Biol. 82, 347-354.

Chauhan, V., Qutob, S.S., Lui, S., Mariampillai, A., Bellier, P.V., Yauk, C.L., Douglas, G.R., Williams, A., and McNamee, J.P. (2007). Analysis of gene expression in two human-derived cell lines exposed in vitro to a 1.9 $\mathrm{GHz}$ pulse-modulated radiofrequency field. Proteomics 7 , 3896-3905.

Friedman, J., Kraus, S., Hauptman, Y., Schiff, Y., and Seger, R. (2007). Mechanism of short-term ERK activation by electromagnetic fields at mobile phone frequencies. Biochem. J. 405, 559-568.

Huang, T.Q., Lee, M.S., Oh, E.H., Kalinec, F., Zhang, B.T., Seo, J.S., and Park, W.Y. (2008). Characterization of biological effect of $1763 \mathrm{MHz}$ radiofrequency exposure on auditory hair cells. Int. J. Radiat. Biol. 84, 909-915.

Huang, T.Q., Lee, M.S., Oh, E.H., Zhang, B.T., Seo, J.S., and Park, W.Y. (2008). Molecular responses of Jurkat T-cells to $1763 \mathrm{MHz}$ radiofrequency radiation. Int. J. Radiat. Biol. 84, 734-741

Lee, J.S., Huang, T.Q., Kim, T.H., Kim, J.Y., Kim, H.J., Pack, J.K., and Seo, J.S. (2006). Radiofrequency radiation does not induce stress response in human T-lymphocytes and rat primary astrocytes. Bioelectromagnetics 27, 578-588.

Lee, M.S., Huang, T.Q., Seo, J.S., and Park, Y.W. (2007). Prediction of the exposure to $1763 \mathrm{MHz}$ radiofrequency radiation based on Gene Expression Patterns. Genomics Inform. 5, 102-106.

Lee, S., Johnson, D., Dunbar, K., Dong, H., Ge, X., Kim,
Y.C., Wing, C., Jayathilaka, N., Emmanuel, N., Zhou, C.Q., Gerber, H.L., Tseng, C.C., and Wang, S.M. (2005). $2.45 \mathrm{GHz}$ radiofrequency fields alter gene expression in cultured human cells. FEBS Lett. 579, 4829-4836.

McNamee, J.P., and Chauhan, V. (2009). Radiofrequency Radiation and Gene/Protein Expression: A Review. Rad. Res. 172, 265-287

Nylund, R., and Leszczynski, D. (2006). Mobile phone radiation causes changes in gene and protein expression in human endothelial cell lines and the response seems to be genome- and proteome-dependent. Proteomics 6, 4769-4780,

Paparini, A., Rossi, P., Gianfranceschi, G., Brugaletta, V., Falsaperla, R., De Luca, P., and Romano Spica, V. (2008). No evidence of major transcriptional changes in the brain of mice exposed to $1800 \mathrm{MHz}$ GSM signal. Bioelectromagnetics 29, 312-323.

Qutob, S.S., Chauhan, V., Bellier, P.V., Yauk, C.L., Douglas, G.R., Berndt, L., Williams, A., Gajda, G.B., Lemay, E., Thansandote, A., and McNamee, J.P. (2006). Microarray Gene Expression Profiling of a Human Glioblastoma Cell Line Exposed In Vitro to a $1.9 \mathrm{GHz}$ Pulse-Modulated Radiofrequency Field. Rad. Res. 165, 636-644.

Sanchez, S., Haro, E., Ruffie, G., Veyret, B., and Lagroye, I. (2007). In Vitro Study of the Stress Response of Human Skin Cells to GSM-1800 Mobile Phone Signals Compared to UVB Radiation and Heat Shock. Rad. Res. 167, 572-580.

Sanchez, S., Masuda, H., Ruffié, G., De Gannes, F.P., Billaudel, B., Haro, E., Lévêque, P., Lagroye, I., and Veyret, B. (2008). Effect of GSM-900 and -1800 signals on the skin of hairless rats. III: Expression of heat shock proteins. Int. J. Radiat. Biol. 84, 61-68.

Takashima, Y., Hirose, H., Koyama, S., Suzuki, Y., Taki, M., and Miyakoshi, J. (2006). Effects of continuous and intermittent exposure to RF fields with a wide range of SARs on cell growth, survival, and cell cycle distribution. Bioelectromagnetics 27, 392-400.

Vanderstraeten, J., and Verschaeve, L. (2008). Gene and protein expression following exposure to radiofrequency fields from mobile phones. Environ. Health Perspect. 116, 1131-1135.

Verschaeve, L. (2009). Genetic damage in subjects exposed to radiofrequency radiation. Mutat. Res. 681, 259-270.

Whitehead, T.D., Moros, E.G., Brownstein, B.H., and Roti Roti, J.L. (2006). Gene expression does not change significantly in C3H 10T (1/2) cells after exposure to 847.74 CDMA or 835.62 FDMA radiofrequency radiation. Radiat. Res. 165, 626-635.

Whitehead, T.D., Moros, E.G., Brownstein, B.H., and Roti Roti, J.L. (2006). The number of genes changing expression after chronic exposure to code division multiple access or frequency DMA radiofrequency radiation does not exceed the false-positive rate. Proteomics 6, 47394744.

Zeng, Q., Chen, G., Weng, Y., Wang, L., Chiang, H., Lu, D., and Xu, Z. (2006). Effects of global system for mobile communications $1800 \mathrm{MHz}$ radiofrequency electromagnetic fields on gene and protein expression in 
MCF-7 cells. Proteomics 6, 4732-1738.

Zhao, R., Zhang, S., Xu, Z., Ju, L., Lu, D., and Yao, G. (2007). Studying gene expression profile of rat neuron exposed to $1800 \mathrm{MHz}$ radiofrequency electromagnetic fields with cDNA microassay. Toxicology 235, 167-175. 